\title{
El uso de las estrategias cognoscitivas en el desarrollo de la comprensión de la lectura de textos escritos en una lengua extranjera
}

\author{
The Use of Cognitive Strategies in the Development of Reading \\ Comprehension of Texts Written in a Foreign Language
}

\author{
José ViLLALOBOS \\ College of Humanities \& Social Sciences \\ Dallas Baptist University, Estados Unidos
}

\section{Resumen}

En este estudio de corte cualitativo, se describió y analizó el papel que juegan el reconocimiento, el uso y la apropiación de las estrategias cognoscitivas de lectura y de las claves lingüísticas en el desarrollo de la comprensión lectora de textos escritos en una lengua extranjera (LE) en un curso de inglés con fines académicos. Se utilizaron algunas herramientas etnográficas para la recolección de los datos y, luego del análisis, emergieron tres categorías diferentes: 1) la importancia de activar el conocimiento previo en la lengua materna (L1) antes de leer el texto escrito en la LE, 2) la identificación de las claves sintácticas y semánticas en el texto escrito en la LE como coadyuvante en la comprensión de la lectura y 3) el uso consciente de las estrategias cognoscitivas de lectura en la LE para el desarrollo de la comprensión lectora. Los hallazgos sugieren que los docentes deberían ayudar a sus estudiantes a activar el conocimiento previo que ellos traen, sobre todo en contextos donde se enseña el inglés con fines académicos. Además, los docentes también deberían orientar a sus estudiantes en la identificación de las claves sintácticas y semánticas del texto escrito en la LE.

Palabras clave: cognición, lectura, comprensión, estrategias cognoscitivas, claves lingüísticas, lengua extranjera, lengua materna 


\begin{abstract}
This qualitative case study described and analyzed the role that recognition, use, and appropriation of cognitive strategies and linguistic cues play in the development of reading comprehension of texts written in a foreign language (FL) in an English-for-AcademicPurposes course. Some ethnographic tools were used for data collection, and three different categories emerged after the data analysis: 1) the importance of activating prior knowledge in the first language (L1), 2) the identification of the syntactic and semantic cues in the text written in the foreign language (FL) as an aid in reading comprehension, and 3) the conscious use of cognitive strategies in the FL for the development of reading comprehension. The findings suggest that teachers should help their students activate their prior knowledge, especially in contexts where English is taught for academic purposes. Besides, teachers should also guide their students in identifying the syntactic and semantic cues of the written text in the FL.
\end{abstract}

Keywords: cognition, reading, comprehension, cognitive strategies, linguistic cues, foreign language, first language

\section{Introducción}

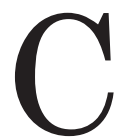

on los avances tecnológicos que se han desarrollado en los últimos años, cada vez se hace más necesario tener acceso al conocimiento que se genera constantemente. Este conocimiento se publica, en la mayoría de los casos, en el idioma inglés. Por lo tanto, es de vital importancia tratar de brindarles oportunidades a nuestros estudiantes universitarios, específicamente, para que puedan abordar y comprender textos escritos en inglés. En muchas ocasiones, algunos estudiantes no saben cómo enfrentar lo que leen en una lengua extranjera (LE), y recurren al uso de su lengua materna (L1) y a otros recursos y estrategias para comprender lo que el escritor ha plasmado en la LE (Cho, Kyoung-Ok y Krashen, 2005).

El uso de la L1 puede considerarse como una alternativa para el aprendizaje de estrategias cognoscitivas de lectura que faciliten, permitan y desarrollen la comprensión de la lectura de textos escritos en la LE (Barnett, 1989; Cho, Kyoung-Ok y Krashen, 2005). En la universidad donde se llevó a cabo este estudio, se han incluido en sus planes de estudios la enseñanza del inglés con fines o propósitos académicos. Algunos docentes de esta área han tratado de hacer énfasis en el uso de la L1 en la enseñanza de la lectura de textos escritos en una LE, con la finalidad de que los estudiantes puedan reconocer y aplicar las estrategias cognoscitivas de lectura que ya poseen en su L1, y las claves lingüísticas del texto en la LE (Cho, Kyoung-Ok y Krashen, 2005).

Algunos docentes de los cursos de Inglés-Lectura, denominados en la literatura especializada como inglés con fines académicos (English for Academic Purposes, EAP, por sus siglas en inglés), tienen como objetivo promover el uso de las estrategias cognoscitivas de lectura y claves lingüísticas en 
un contexto auténtico de enseñanza/ aprendizaje de la lectura de textos escritos en inglés. Hutchinson y Waters (1987), Hyland $(2006,2018)$ y Wingate y Tribble (2012) señalan que los cursos de inglés con fines académicos son cursos dirigidos a aquellas personas que tienen necesidad de conocer la LE para propósitos tales como la lectura de textos técnico-científicos en el área de estudio que les permita obtener la información directamente del autor.

El objetivo principal de los cursos de Inglés-Lectura que se dictan en la universidad en cuestión es desarrollar en los estudiantes el uso de estrategias cognoscitivas de lectura (inferencia, muestreo, confirmación/descarte y finalización) y de las claves lingüísticas (grafofónicas, sintácticas, semánticas y pragmáticas) para el logro de la comprensión de la lectura (Klingner, Vaughn y Boardman, 2015; Goodman, 1968; Maming, 2019; Weaver, 2002). En estos cursos de lectura con fines académicos, los estudiantes abordan textos escritos en inglés como LE, pero reflejan su comprensión del texto en forma oral y escrita en la L1, en este caso, el español. Es importante señalar que algunos docentes de los cursos de Inglés-Lectura utilizan textos escritos en la LE en las asignaturas que componen el plan de estudios, las cuales cubren las necesidades académicas que los estudiantes tienen acerca de un área o tema en particular.

En algunas ocasiones, estos estudiantes universitarios presentan problemas al momento de abordar un texto escrito en una LE. Estos problemas se hacen cada vez más significativos y evidentes, y una razón podría ser que estos estudiantes no reconocen sus estrategias cognoscitivas de lectura en su L1. Esto se debe mayormente a que no existe una conciencia y conocimiento por parte del estudiante acerca del proceso de la lectura cada vez que lee un texto. Con el fin de promover el desarrollo de la comprensión de la lectura de textos escritos en inglés como LE, se llevó a cabo un estudio de caso cualitativo con el propósito de analizar el papel que juega el reconocimiento, el uso y la apropiación de las estrategias cognoscitivas de lectura y de las claves lingüísticas en el desarrollo de la comprensión de la lectura en un curso de inglés con fines académicos. Por lo tanto, el desarrollo de esta investigación muestra una nueva visión de la enseñanza de la lectura con fines académicos, para aquellos docentes de Inglés-Lectura que han observado que sus estudiantes presentan problemas al abordar textos escritos en inglés como LE relacionados con sus áreas de estudio, y que no están en capacidad de utilizar las estrategias cognoscitivas pertinentes para el logro de la comprensión de la lectura.

\section{Preguntas de la investigación}

A fin de llevar a cabo este estudio de corte cualitativo, se formularon las siguientes preguntas que sirvieron de directrices para el desarrollo de esta investigación:

1. ¿Cuál es el papel que juegan las estrategias cognoscitivas de lectura en el desarrollo de la comprensión de la lectura de textos escritos en inglés en un curso con fines académicos? ¿De qué manera las estrategias cognoscitivas de lectura sirven de base para el desarrollo de la 
comprensión de la lectura de textos escritos en una LE?

2. ¿Cómo se evidencia el uso de las estrategias cognoscitivas de lectura en un curso de inglés con fines académicos?

a. ¿Qué tipo de actividades de lectura en la L1 sirven de base para el desarrollo de estrategias cognoscitivas de lectura cuando los estudiantes abordan textos escritos en la LE?

b. ¿Hasta qué punto reconocen los estudiantes sus estrategias cognoscitivas de lectura en la L1 para el desarrollo de la comprensión de textos escritos en la LE?

\section{Marco teórico}

Un principio fundamental en el desarrollo de las estrategias cognoscitivas de lectura es la interdependencia lingüística entre la adquisición de la lengua y las estrategias cognoscitivas de lectura y de escritura en la L1 y en la LE (Grabe y Stoller, 2013; Kerper, 2002). La interdependencia lingüística se refiere al conocimiento y empleo de estrategias cognoscitivas de lectura particulares en la L1 que pueden ser utilizadas en la lectura de textos escritos en una LE, las cuales pueden incluir estrategias de reconocimiento de palabras, activación del conocimiento previo, formación de esquemas, inferencia, entre otras (Alderson, Brunfaut y Hardin, 2017; Cohen, 2014; Grabe y Stoller, 2013). Según Kerper (2002), la mayoría de los docentes de una LE creen en el rol positivo y en la influencia de la L1 en el desarrollo de habilidades cognoscitivas, así como en el valor de la enseñanza de la L1 en la construcción de la identidad sociocultural como una forma aplicable a la implementación efectiva de los programas de educación relacionados con el área de lectura en una LE. En este sentido, la teoría sociocultural nos ayuda a comprender cómo el humano no actúa directamente en respuesta al mundo físico, sino en función de herramientas y de la labor de una actividad, la cual nos permite cambiar el mundo (Lantolf y Poehner, 2014; Vygotsky, 1978).

Strauss, Goodman y Paulson (2009) argumentan que el desarrollo de las estrategias cognoscitivas de lectura se refiere a aquellas de las cuales el lector se ha apropiado y puede utilizar cuando aborda el texto escrito. Goodman (1982) describió las estrategias cognoscitivas de lectura dentro de su Modelo Socio-Psicolingüístico-Transaccional de la Lectura. Este modelo explica que, durante el proceso de lectura, el lector dispone de cuatro tipos de información cuando utiliza el lenguaje. Esta información proviene de cuatro sistemas lingüísticos: (1) sistema grafofónico, (2) sistema sintáctico, (3) sistema semántico y (4) sistema pragmático.

De acuerdo con el Modelo SocioPsicolingüístico-Transaccional de la Lectura, las estrategias cognoscitivas que el lector utiliza para construir significado son las siguientes: iniciación/ reconocimiento, muestreo/selección, predicción/inferencia, confirmación/ descarte y corrección/finalización (Dechant, 2009; Maming, 2019; Ramírez, 2003; Rumelhart, 1980; Strauss, Goodman y Paulson, 2009):

Estrategias de iniciación/reconocimiento: el lector decide en qué momento necesita utilizar sus estrategias y activar sus esquemas de acuerdo con el propósito del acto de 
lectura. Así, el lector reconoce el material impreso e inicia su lectura. El lector comienza a construir significado cuando empieza a leer mediante la activación de sus esquemas mentales y el uso de sus estrategias cognoscitivas y sus procesos lingüísticos (Strauss, Goodman y Paulson, 2009).

Estrategias de muestreo/selección: el lector desarrolla estrategias de muestreo y selección cuando identifica las señales gráficas y la estructura del texto para elegir las que considera útiles y así confirmar una imagen perceptual. En este sentido, el lector no utiliza toda la información visual, ya que el sistema grafofónico no garantiza la comprensión. El lector selecciona la información visual necesaria basado en su conocimiento previo acerca de la lengua, así como del conocimiento de la estructura textual del escrito (Strauss, Goodman y Paulson, 2009).

Estrategias de predicción/inferencia: el lector construye esquemas en su intento por comprender el texto escrito. En este momento el lector predice, es decir, hace uso de sus esquemas mentales para anticiparse a lo que encontrará en el texto y cuál podría ser su significado. El lector realiza inferencias de la información, aunque esta no esté explícita en el texto. La inferencia le permite al lector complementar la información disponible utilizando el conocimiento conceptual y lingüístico y los esquemas mentales que ya posee. El muestreo, la predicción y la inferencia son estrategias cognoscitivas básicas de la lectura, y el lector las utiliza para controlar su proceso con el fin de asegurarse de que lo leído tenga sentido (Strauss, Goodman y Paulson, 2009).
Estrategias de confirmación/ descarte: algunas veces el lector hace predicciones que luego resultan ser falsas o sin fundamento. Por esta razón, el lector utiliza las estrategias de confirmación o descarte para corroborar o rechazar las predicciones elaboradas con base en su conocimiento previo y en sus experiencias previas (Hardin, 2001; Strauss, Goodman y Paulson, 2009).

Estrategias de corrección/finalización: de igual modo, el lector utiliza estrategias de corrección para considerar la información que tiene, y obtener más información cuando no puede confirmar sus predicciones. Esto implica un repensar o una regresión hacia partes anteriores del texto, buscando así información útil y adicional. Por último, el lector desarrolla estrategias de finalización para elegir el momento cuando va a culminar su lectura. El lector finaliza su lectura cuando logra construir significados; sin embargo, el lector puede detener su lectura por otras razones, entre las cuales se destaca, principalmente, la carencia de conocimiento previo. Cuando la lectura no termina en la construcción de significado por parte del lector, se produce entonces lo que Goodman (2014) denominó un cortocircuito. Este fenómeno ocurre por las siguientes razones: a) el lector pierde la estructura del texto y no construye significados, b) el lector no utiliza sus estrategias cognoscitivas de manera apropiada, c) el lector ha sido sometido a métodos de enseñanza de la lectura que le permitieron pensar que leer es pronunciar palabras y, en consecuencia, solo utiliza el sistema grafofónico para la ejecución de su proceso.

Los sistemas lingüísticos le permiten al lector obtener cierto tipo de información que servirá de base para 
la construcción del significado, y que, a su vez, servirá de puente entre las transacciones que el lector realizará entre su conocimiento previo (esquemas mentales) y el contexto en el que se encuentra el texto.

\section{Metodología}

Con la finalidad de dar respuestas a las preguntas de investigación que orientan este artículo, se utilizó el estudio de caso como diseño de investigación. Creswell y Creswell (2018) explican que el estudio de caso es un tipo de examen completo o intenso de una faceta, una cuestión o quizás unos acontecimientos que tienen lugar en un marco geográfico a lo largo del tiempo. Yin (2018) considera al estudio de caso como una forma particular de recoger, organizar y analizar datos. Este diseño de investigación permite indagar en profundidad un tema objeto de estudio, así como la comprensión de problemas o fenómenos que se presentan en un grupo social determinado partiendo de las interpretaciones de los propios actores (Merriam, 2016).

\section{Lugar de la investigación y de los participantes}

Para llevar a cabo esta investigación se seleccionó un curso de Inglés-Lectura de las carreras Historia, Letras y Medios Audiovisuales, perteneciente a una universidad venezolana ubicada en el occidente del país. La asignatura está dividida en tres niveles; sin embargo, para efectos de esta investigación solo se tomó en cuenta los estudiantes del tercer nivel del curso. Según el plan de estudios y el programa de esta asignatura, se supone que estos estudiantes ya tienen un conocimiento más avanzado del inglés como LE; por ende, la decisión de escoger este nivel. La selección del lugar de la investigación también estuvo sujeta a que la docente, Julia (seudónimo que ella misma eligió), de este curso de Inglés-Lectura contempla, como uno de los objetivos del curso, el uso y desarrollo de estrategias cognitivas de lectura y claves lingüísticas cuando los estudiantes abordan textos escritos en inglés. Además, y debido a conversaciones informales previas que se tuvieron con la docente, ella implementa actividades que facilitan el reconocimiento, uso y apropiación de varias estrategias cognoscitivas para el desarrollo de la comprensión de la lectura, lo cual permitió observar si los estudiantes hacían uso de sus propias estrategias cognitivas de lectura al momento de abordar textos escritos en una LE con fines académicos y, de ser así, analizar cómo los estudiantes mostraban su comprensión del texto escrito en la L1, a través de las actividades diseñadas e implementadas por la docente.

Los informantes de la investigación fueron tres estudiantes del tercer nivel de Inglés-Lectura (Frank, Angélica y Mayela, seudónimos que ellos mismos seleccionaron y que se usaron para guardar su confidencialidad). Aunque varios estudiantes cumplieron con los requisitos que se pidieron para participar en el estudio, se escogieron solo tres estudiantes, ya que el propósito no fue representar todo el universo, sino el caso solamente (Yin, 2018). La selección de los estudiantes estuvo sujeta al: 1) deseo voluntario de los informantes para participar en el estudio, 2) deseo voluntario de ser entrevistados, 3) deseo voluntario 
de compartir sus documentos escritos y 4) deseo voluntario de realizar los protocolos de pensamiento en voz alta. Generalmente, estos cursos constan de un grupo no mayor de 35 estudiantes, en edades comprendidas entre 18 y 25 años, y cursan bien sea el quinto o sexto semestre de su carrera. A todos los participantes (estudiantes y docente), se les informó sobre el objetivo de la investigación, el rol de los que cumplirían, y el proceso de recolección de los datos.

\section{Rol del investigador}

En el caso del investigador, la actuación en el aula de clase fue de observador-participante. Merriam (2016) señala que el observador-participante es absorbido por lo que observa, por lo que recuerda y por lo que graba en las entrevistas. Su participación en el aula no muestra ningún tipo de contacto, en cuanto a la intervención pedagógica se refiere, pero sí participa en el momento de recoger los datos.

\section{Procedimiento de recolección de los datos}

Las herramientas etnográficas de investigación para la recolección de los datos fueron la observación, la conducción de entrevistas semiestructuradas, la realización de protocolos de pensamiento en voz alta y el análisis de documentos escritos. El período de recolección de los datos fue de dieciocho semanas de clases de 1 hora y 30 minutos cada una, establecidas para los cursos de Inglés-Lectura adscritos a las carreras de régimen semestral.

Las observaciones que se llevaron a cabo fueron registradas en una hoja de observación (ver Anexo 1), lo que permitió que el investigador pudiera recoger y reflejar de forma sistemática la información, tomar notas de lo que ocurrió en el campo, su percepción de lo observado y comentarios generales de lo que sucedió. Esta hoja de observación preliminar fue diseñada para obtener los datos pertinentes en cada una de las clases, y estuvo sujeta a modificaciones, dependiendo de la información que se recogiera y de los eventos que ocurrieran durante las sesiones de clase.

La hoja de observación está compuesta por tres columnas: la primera columna se usó para describir cada uno de los eventos, actividades, conversaciones u otros que se suscitaron en el aula de clase; la segunda columna incluyó la percepción del investigador sobre lo observado; la tercera columna plasmó los comentarios generales de otros eventos que ocurrieron durante la clase, conexiones entre lo que se observó y las propias percepciones del investigador, y que fueron registradas luego de haber culminado la sesión de clase.

\section{Entrevistas semiestructuradas}

En el desarrollo de esta investigación se llevaron a cabo tres entrevistas semiestructuradas que fueron grabadas y que tuvieron una duración aproximada de 45 minutos cada una. El investigador también fomentó conversaciones informales con los participantes con el objeto de conocerlos de manera personal, y tener una idea sobre su conocimiento de la LE. Las entrevistas semiestructuradas se realizaron una al inicio, una a la mitad y otra al final del semestre. La primera entrevista tuvo el fin de ahondar sobre el conocimiento de los estudiantes acerca de la lectura. Los temas que se trataron en la primera 
entrevista fueron: 1) la definición de la lectura, 2) los tipos de textos que leen, 3) el conocimiento del inglés como LE y 4) el contacto con el inglés en cursos de inglés (ver Anexo 2 (a)). Luego de algunas sesiones de clase, se llevó a cabo la segunda entrevista, cuyo principal objetivo fue indagar sobre las impresiones que tuvieron los estudiantes en cuanto al uso de las estrategias cognoscitivas para el desarrollo de la comprensión de la lectura. Los temas que se abordaron fueron los siguientes: 1) el papel que juegan las estrategias cognoscitivas de lectura en el desarrollo de la comprensión de la lectura de textos escritos en inglés, 2) lo que los estudiantes hacen para abordar los textos escritos en la L1 y en la LE y 3) el conocimiento que tienen los estudiantes sobre las estrategias de lectura (ver Anexo 2 (b)). El objetivo de la última entrevista que el investigador tuvo con los estudiantes fue explorar más a fondo sus impresiones acerca de las actividades desarrolladas durante el curso. Estas impresiones fueron recogidas a través de preguntas sobre temas tales como: 1) las estrategias cognoscitivas de lectura como base para el desarrollo de la comprensión de la lectura de textos escritos en una LE, 2) las evidencias del uso de las estrategias cognoscitivas de lectura en un curso de inglés con fines académicos y 3) el uso de las estrategias cognoscitivas de lectura para el desarrollo de la comprensión de la lectura y la importancia de esas estrategias al momento de abordar un texto escrito en una LE (ver Anexo 2 (c)). Esta lista de tópicos fue ampliada a lo largo del desarrollo de las entrevistas.

Con relación a la docente, se llevó a cabo una entrevista al inicio del semestre y otra al final. La primera entrevista tuvo como objetivo conocer algunos aspectos relacionados con el desarrollo de la clase, y la concepción de la docente en cuanto a la lectura de textos escritos en inglés como LE. Entre los temas tratados en la primera entrevista se encuentran: 1) la concepción de la lectura, 2) el desarrollo de las estrategias cognoscitivas de lectura y 3) el tipo de actividades diseñadas para el logro de la comprensión de la lectura de textos escritos en inglés como LE (ver Anexo 3 (a)). La segunda entrevista tuvo como finalidad comprobar y profundizar más en torno a la concepción de la lectura previamente señalada por la docente, y sus consideraciones acerca del progreso de los estudiantes en cuanto al nivel de comprensión de los textos escritos en inglés, partiendo de las actividades diseñadas e implementadas durante el semestre. Algunos temas de esta entrevista abarcaron aspectos como: 1) las estrategias cognoscitivas de lectura como base para el desarrollo de la comprensión de la lectura de textos escritos en una LE, 2) las actividades de lectura en la L1 que sirvieron de base para el desarrollo de estrategias cognoscitivas de lectura cuando los estudiantes abordaron textos escritos en la LE y 3) el reconocimiento de las estrategias cognoscitivas de lectura por parte de los estudiantes (ver Anexo 3 (b)). Al igual que en el caso de los temas para los estudiantes-informantes, esta lista de tópicos también fue ampliada con base en las observaciones de clase.

\section{Protocolos de pensamiento en voz alta}

La técnica de los protocolos de pensamiento en voz alta tuvo como objetivo mostrar cómo los estudiantes verbalizaron sus pensamientos a medida que ellos leían el texto escrito en la LE, y cómo solucionaron sus problemas de 
comprensión de la lectura a través de la aplicación de las estrategias cognitivas y el uso de las claves lingüísticas. Estas verbalizaciones del participante incluyeron preguntas y comentarios sobre el texto escrito, así como reflexiones de cómo ellos utilizaron su conocimiento previo, realizaron inferencias o predicciones y llegaron a conclusiones sobre el contenido del texto. Durante el proceso de recolección de los datos se aplicó esta técnica en dos oportunidades: una al inicio del semestre, con el fin de discernir si los estudiantes poseían, reconocían y manejaban sus estrategias y las claves lingüísticas y otra, al final del semestre, con el objetivo de determinar si los estudiantes reforzaron esas estrategias que ya poseían, y de qué forma el uso de estas les permitió lograr la comprensión del texto escrito en la LE.

\section{Documentos escritos}

Con el fin de observar la efectividad del reconocimiento, uso y apropiación de las estrategias cognoscitivas de lectura como un vehículo para resolver los problemas de comprensión de la lectura en la LE, el investigador analizó documentos escritos realizados por los estudiantes. Entre estos documentos se encuentran el programa de la asignatura Inglés-Lectura, los borradores de las actividades realizadas en forma escrita (resúmenes, organizadores gráficos, versiones escritas, entre otros) que se encuentran reflejados en el programa de la asignatura y que la docente implementó a lo largo del semestre.

\section{Análisis e interpretación de los datos}

El análisis de los datos se realizó simultáneamente a su recolección; esto con el fin de clasificar y categorizar la información que sirvió de base para la triangulación, que permitió la generación de categorías de unidades de significado que fueron cotejadas con los datos y las categorías obtenidas de otras fuentes de información (Denzin y Lincoln, 2018). Creswell y Creswell (2018) señalan que la triangulación impide que se acepte fácilmente la validez de las impresiones iniciales del investigador, lo cual amplía el ámbito, densidad y claridad de las categorías desarrolladas en el transcurso de la investigación.

La triangulación estuvo basada en el análisis de información proveniente de las observaciones, las entrevistas semiestructuradas y las conversaciones informales, los protocolos de pensamiento en voz alta, los documentos escritos y la fundamentación teórica en que se basó este estudio. Para el análisis de los datos el investigador utilizó cuadros comparativos de las preguntas y respuestas que surgían de los temas de las entrevistas. Además, el uso de colores también permitió relacionar y diferenciar la información obtenida de los instrumentos de recolección de los datos. La información que surgió de la triangulación de los datos sirvió de base para la construcción y análisis de las categorías emergentes y que dieron respuesta a las preguntas de investigación.

\section{Limitaciones de la investigación}

En esta investigación, se analizó cómo los estudiantes hicieron uso de sus estrategias cognoscitivas de lectura en la lengua extranjera para el logro de la comprensión de la lectura de textos escritos en un curso de Inglés-Lectura dirigido a la enseñanza del inglés con fines académicos, perteneciente a un pénsum 
de una universidad pública venezolana. Aunque esta situación pudiera presentarse en varios ambientes y niveles educativos diferentes, no es un atenuante para considerar que todos los docentes de lenguas con fines académicos enfrentan esta misma situación. La pertinencia de este estudio está dada, en este caso, en mostrar evidencias de cómo los estudiantes de los cursos de Inglés-Lectura de las carreras de Historia, Letras y Medios Audiovisuales reconocen, aplican y desarrollan las estrategias cognoscitivas de lectura al momento de abordar un texto escrito en inglés, logrando así la meta del lector en una LE: la comprensión del texto escrito. Por lo tanto, los resultados que se obtuvieron en este estudio no pueden ser generalizados a otros ambientes o contextos socioeducativos.

\section{Resultados}

Los resultados de este estudio se ven reflejados a través de las categorías que emergieron luego de haber triangulado toda la información. Entre las categorías emergentes se encuentran: 1) la activación del conocimiento previo en la L1, 2) las claves lingüísticas en el texto escrito en la LE y 3) el uso de las estrategias cognoscitivas de lectura.

\section{La activación del conocimiento previo en la L1: ¿Puente para la comprensión?}

Cuando los estudiantes hacían referencia a la importancia de la L1 durante las entrevistas semiestructuradas y las conversaciones informales, ellos señalaban que una de las ventajas radicaba en que la activación del conocimiento previo servía como puente entre lo que ellos conocían sobre el tema y la información presente en el texto escrito. En una entrevista, Frank señaló: "Haber activado mi conocimiento previo sobre el tema de la Guerra Civil Española me facilitó la lectura del texto escrito en inglés, ya que hice conexiones entre lo que yo sabía y la información que me estaba presentando el texto escrito en inglés". Por su parte, Angélica recalcó, a través de un ejemplo, la importancia de activar su conocimiento previo al manifestar lo siguiente: "Cuando yo activo mi conocimiento previo sobre el tema del teatro en español se me hace más fácil comprender lo que dice el texto en inglés, porque conecto la información". Al igual que Frank y Angélica, Mayela afirmó que para ella era "importante activar el conocimiento previo en español". Esta informante manifestó lo siguiente: "El conocimiento previo me ayudaba a hacer las conexiones con el tema y el texto en inglés". Estas afirmaciones muestran la importancia que tuvo para los estudiantes el haber activado su conocimiento previo, consolidándose, de esta manera, información antes de abordar el texto escrito en inglés (Dole et al., 1991; Graves y Cook, 1983; Stevens, 1982).

Otra evidencia de la importancia del conocimiento previo fueron las actividades realizadas en el aula de clases con el "Texto Base" (TB) —el cual fue seleccionado a través de la negociación del tema entre la docente y los estudiantes, y trabajado en forma grupal en el aula de clases-durante la etapa de prelectura, en donde los estudiantes mostraban cuánto conocían sobre ese tema en particular. Luego de investigar y profundizar más sobre la Guerra Civil Española, uno de los temas seleccionado por la docente, los estudiantes estaban preparados para abordar el escrito en inglés. Esta activación del 
conocimiento previo era revisada por los estudiantes tanto en forma individual como grupal; de esta manera, todos los estudiantes de la clase podían ampliar su conocimiento o la información que habían escrito en sus mapas semánticos, y enriquecer así lo que ellos conocían mediante consultas en fuentes bibliohemerográficas o electrónicas. Este enriquecimiento les permitía a los estudiantes saber cuánto conocían sobre el tema, y lo que necesitaban investigar o profundizar antes de abordar el escrito en inglés.

Durante las actividades que correspondían al Nivel III de Inglés-Lectura, los estudiantes realizaron dos lecturas: una denominada TB y un "Texto Satélite" (TS) —el cual fue escogido por los estudiantes en forma individual, y trabajado con la docente en tutorías individuales para la posterior elaboración de mapas semánticos y reflexiones escritas- Como actividad de prelectura del TB, los estudiantes activaron su conocimiento previo sobre el posible contenido del tema, por medio de una serie de preguntas elaboradas por la docente y de la realización de mapas conceptuales con base en las respuestas provistas por los estudiantes (Rowe y Rayford, 1987). Estas preguntas orientaban a los estudiantes sobre cuánto conocimiento tenían sobre el tema. Las respuestas eran organizadas por los estudiantes en categorías. Por supuesto, las preguntas eran una guía para que los estudiantes comenzaran a realizar su organizador gráfico de información, lo que no los coartaba para que incorporaran toda la información que conocían o investigaban sobre el tema.

Cada uno de estos mapas estaban acompañados de una reflexión escrita que les permitía a los estudiantes evaluar su conocimiento sobre la Guerra Civil Española, por ejemplo, y cómo podrían ampliar este tema. La activación del conocimiento previo por medio de la elaboración de estos mapas permite señalar que el conocimiento previo funge, en esta etapa de la lectura de los textos escritos en inglés como LE, como el puente entre lo que los estudiantes conocen sobre el tema y la información que les proveerá el texto escrito en el momento de ser abordado por los estudiantes (Al-Ghazo, 2015; Heimlich y Pittelman, 1991). Con respecto a la elaboración de los mapas, la docente expresó lo siguiente durante la sesión de clase número seis:

El conocimiento previo que yo tengo sobre el tema, ese conocimiento previo sobre el tema va a estar fundamentado en los mapas semánticos, uno inicial, que es donde yo reviso a ver cómo estoy, y otro donde yo alimento esa información como un álbum que queda, que puedo visitar aquí ¿Ok? Entonces, ¿cómo haría yo para contestar? ¿Quién quiere hacerlo? ¿Cómo haría yo para mi primera reflexión sobre consideraciones sobre mi conocimiento previo? ¿Cómo podría hacer la reflexión de lo que debería hacer ahí? No me van a presentar el mapa semántico número uno y el número dos, así como así. Debe haber una transición entre el uno y el otro con una pequeña reflexión, una explicación. Los estudiantes deben responder y explicar: ¿qué pasó?, ¿qué están haciendo? y ¿por qué lo hicieron? Es decir, no es que van a presentar los dos mapas de una vez. Claro, van a ser diferentes; uno va a ser más abundante que el otro, 
más explicito, más rico, pero tiene que haber un puente de reflexión entre uno y otro, y esas preguntas que ustedes ven allí van a ayudar a construir ese puente... ¿Ok?
La figura n. ${ }^{\circ} 1$ presenta un ejemplo del mapa semántico elaborado por Mayela, durante la etapa de activación del conocimiento previo.

\section{Figura 1}

Mapa semántico. Informante: Mayela -- TB: Spanish Civil War exhibition

ESCALÓN NN 1: SOBRE EL CONOCIMIENTO PREVIO DEL TEMA QUE SE DESARROLLARÁ O SE TRATARÁ EN EL TEXTO

- CONSIDERACIONES SOBRE MI CONOCIMIENTO PREVIO EN RELACIÓN CON EL TEMA QUE TRATARÉ EN EL TEXTO
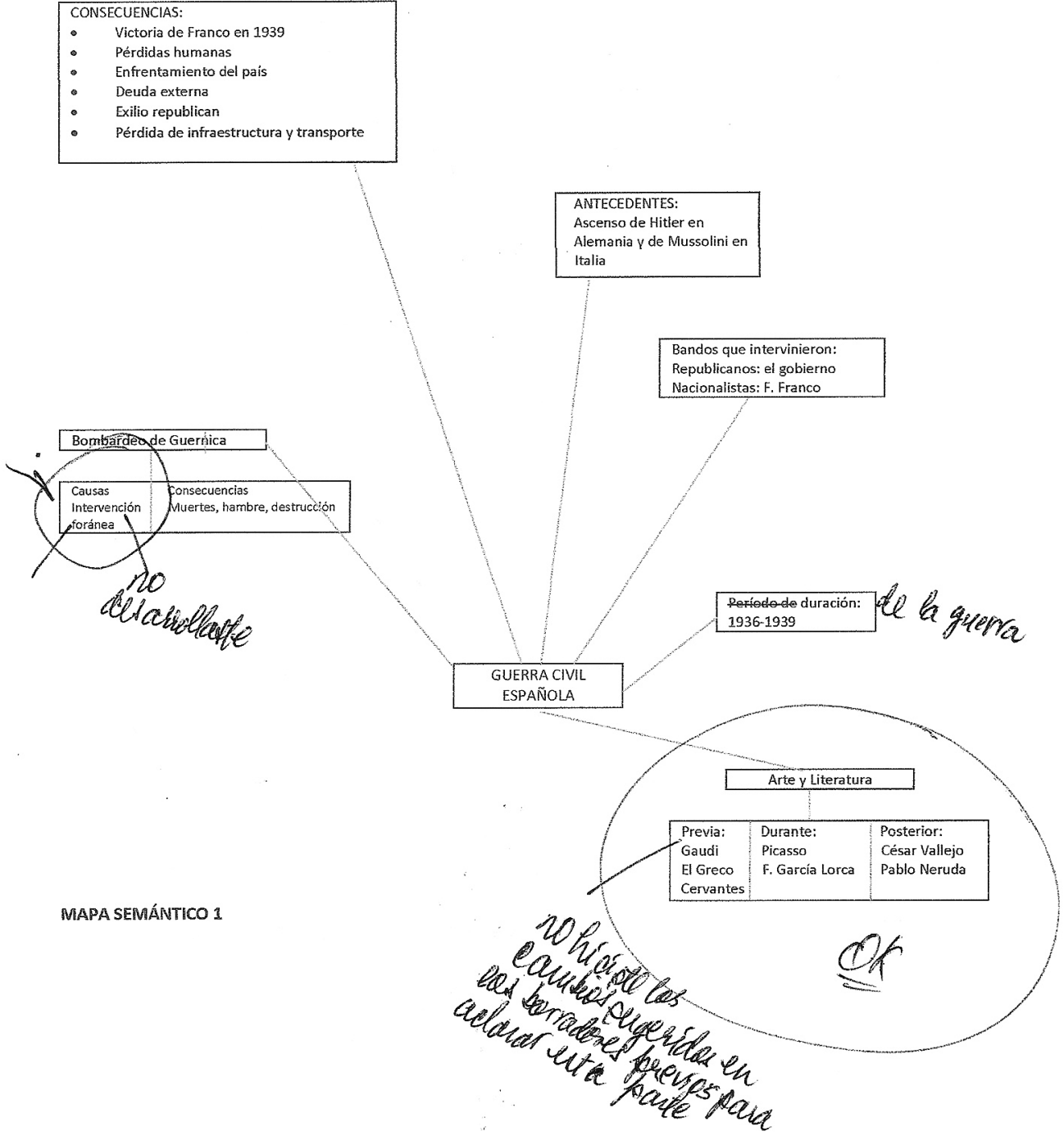

MAPA SEMÁNTICO 1

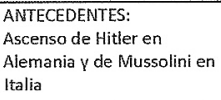


El mapa semántico realizado por Mayela y revisado y corregido por la docente es una muestra de la actividad inicial que los estudiantes realizaron en las sesiones de clase durante la etapa de prelectura y antes de abordar el TB. Mayela reflejó su conocimiento a partir de lo que ella conocía, ya que la Guerra Civil Española es un tema que está incluido en el contenido programático de una de las asignaturas del pénsum de estudios.

Estos mapas conceptuales elaborados por los estudiantes son evidencia de cómo ellos evaluaban cuánto conocían sobre el tema. Esto significó que los estudiantes debían revisar sus conocimientos previos y experiencias sobre el tema antes de abordar el texto escrito, lo cual les permitía, a lo largo de la lectura, revisar si la información presente en sus mapas se encontraba allí, y qué nueva información podrían incorporar. Estos mapas eran retomados por los estudiantes en sesiones de clases posteriores, para confirmar o descartar si su conocimiento previo se acercaba a la información presente en el texto escrito en la LE o qué nuevo conocimiento les proveyó el texto escrito.

\section{Claves lingüísticas en el texto escrito en la LE: ¿Coadyuvantes para la com- prensión de la lectura?}

Juntamente con el uso de las estrategias cognoscitivas de lectura, se encuentran las claves lingüísticas, las cuales son utilizadas por el lector a medida que va abordando un texto escrito. En la lectura de escritos en la LE con fines académicos, Julia señalaba que se activaban las claves sintácticas (aspectos gramaticales y de vocabulario) y semánticas (cognados), en conjunto con el desarrollo de las estrategias cognoscitivas de lectura. Durante las observaciones de clases, se notó cómo los estudiantes realizaban conexiones entre la L1 y la LE, tanto de aspectos gramaticales como de vocabulario, partiendo del conocimiento que tienen de ambas lenguas. A continuación, se muestra cómo los estudiantes hicieron uso de las claves sintácticas y semánticas para la comprensión de estos escritos en una LE.

Claves sintácticas: aspectos gramaticales y uso de vocabulario

Durante las sesiones de clase, se observó cómo los estudiantes, guiados por la docente, señalaban las dificultades que ellos encontraron en el texto escrito en inglés, en relación con los aspectos gramaticales y de vocabulario. En una sesión de clase, los estudiantes, juntamente con la docente, analizaron el contenido del primer segmento del TB (Spanish Civil War exhibition), con el fin de conocer cuánto habían comprendido. Para ello, Julia les solicitó a algunos estudiantes que leyeran sus versiones escritas sobre lo que habían comprendido. Luego de que cada uno de ellos terminó de leer su versión, la docente y los estudiantes analizaron el contenido de las versiones, deduciendo, en algunos casos, que muchas de estas versiones eran traducciones literales o traducciones de cada una de las palabras que contenía el texto. Estas traducciones, según Julia, interrumpían la comprensión del texto $y$, en algunos casos, reflejaban una tergiversación del contenido.

La docente, mediante de las lecturas de las versiones individuales de cada segmento y de cada oración que componía el texto escrito, orientaba a los estudiantes a identificar y resolver, por medio del 
contexto, los problemas de estructuras gramaticales y vocabulario presentes en el escrito. Los problemas de comprensión de estructuras gramaticales y vocabulario expuestos por los estudiantes eran leídos en voz alta, para que el resto de la clase participara en la resolución de estos problemas. Esta actividad permitía que aquellos estudiantes con menos dificultades en la comprensión de las estructuras y vocabulario fungieran como compañeros más capaces (Vygotsky, 1978).
A continuación, se presenta una situación de clase en la que Julia orientaba a los estudiantes, durante la etapa de lectura, para que identificaran la función gramatical de la palabra its (cuyo significado en español es "suyo — de él o ella-", para animales o cosas en singular), la cual les estaba causando problemas a algunos de los estudiantes en cuanto a la comprensión de la primera oración presente en el segmento n. $^{\circ} 1$ del TB: Spanish Civil War exhibition.

\section{Figura 2}

Primer párrafo del TB: Spanish Civil War exhibition, donde aparece el aspecto gramatical tratado en clase

\section{The Spanish Civil War}

The Spanish Civil War was a complex conflict that had an impact far beyond the boundaries of Spain.

Sixty-years after its outbreak it continues to generate debate.

En esta sesión de clase, Julia orientó a los estudiantes para que identificaran la función gramatical en el contenido del texto. El estudiante que participa en esta conversación es una joven que no fungió como informante en la investigación.

Julia: ¿Cómo interpretaron el significado de la palabra its, a partir del contexto?

Estudiante:... "su", según el contexto. Julia: Sí, eso es lo que significa porque su función gramatical es adjetivo posesivo y hace referencia a la palabra it en el texto.

La docente, con la ayuda de la estudiante, solucionó el problema que se estaba suscitando en el grupo con respecto al significado del adjetivo posesivo its, el cual estaba interrumpiendo la comprensión de la oración, ya que algunos estudiantes no estaban incluyendo dichas palabras en sus versiones escritas. Aunque para muchos estudiantes esto no fue un problema mayor, Julia orientó a todos los estudiantes a buscar soluciones inmediatas en cuanto a las estructuras gramaticales que ellos podían resolver por conocimiento de la LE o por medio del contexto en donde se encontraban insertadas las estructuras gramaticales. Por supuesto, esta solución se dio en este caso, ya que una estudiante del grupo, que no formaba parte de mis informantes, conocía el significado de la estructura gramatical en la LE.

La figura $n .{ }^{\circ} 3$ muestra la versión del párrafo 1, segmento 1, TB: Spanish Civil War exhibition, realizada por Angélica, donde aparece la función gramatical, luego de revisadas las versiones en la clase. 
Figura 3

Versión del párrafo 1, segmento 1, TB: Spanish Civil War exhibition, donde aparece la función gramatical, realizada por Angélica

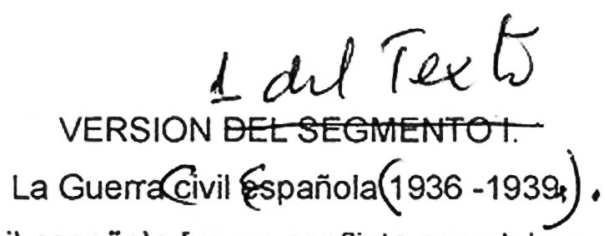

La guerra civil española fue un conflicto complejo que tuvo un impactg? más allá de los límites de España. Después de tanto tiempo de súfinicio? sigue generando discusiones.

La guerra se inició con una sublevación militar el 17 de julio de 1936 en Marruecos español.y el dia siguiente en el continente, los oficiales derechistas se revelaron contra el gobierno, de lafegundaRepublica yansus reformas sociales. Se oponian a las medidas amenazando con debilitar el poder de la tiglesia, a las fuerzas armadas y a las concesiones regionales autónomas de las regiones catalanas y vascas.

Frank, por su parte, comentó sobre la manera cómo había resuelto las dudas en cuanto a vocabulario, usando el diccionario y el contexto; este último lo ayudó a escoger la acepción correcta.. Los ejemplos acerca de las dudas en cuanto a los aspectos gramaticales y al vocabulario son una muestra de las actividades realizadas por los estudiantes durante la etapa de lectura, para lograr la comprensión del texto escrito en la LE.

En conversaciones informales con los estudiantes, ellos señalaron que debían reflexionar acerca de cómo resolvieron las dudas gramaticales surgidas tanto con el TB como con el TS. Por ejemplo, Mayela consideraba que las explicaciones de la docente y las reflexiones escritas le permitieron realizar un análisis más minucioso del vocabulario que no entendía del texto.
Mayela explicó cómo trabajó en el reconocimiento o identificación del vocabulario durante la etapa de lectura, y cómo hizo las conexiones entre la L1 y la LE. Mayela también describió cómo realizó esta actividad, explicando el proceso de la siguiente manera:

Realizo una primera lectura donde identifico las palabras que no sé. Lo que entendí, lo escribo en español, voy al diccionario y busco aquellas palabras que no comprendí y las comparo con el español, ya he dejado los espacios en el texto en español para insertar esas palabras. Hago una nueva lectura para comparar si lo que realmente comprendí entra en el texto, en el contexto del texto; de lo contrario, trato de profundizar más en las palabras que están dentro de la frase 
que yo he entendido, pero que en el contexto puede significar otra cosa. Un ejemplo es la palabra play que yo creía era juego y me di cuenta de que era obra, cuento, artículo, cuando consulté el diccionario. Además, la ayuda de la profesora me orientó para determinar si era correcta o no.

Estas mismas explicaciones del proceso de reconocimiento de vocabulario y del proceso de la lectura fueron provistas por Angélica y Frank, con el propósito de demostrar cómo realizaron esos procesos. En este particular, Frank señaló lo siguiente:

El abordaje que hago de la lectura tanto en español como en inglés puede presentar ciertas similitudes porque en ambos casos recurro a los conocimientos previos que poseo sobre el tema, luego utilizo la gramática y, con la ayuda del contexto, preciso el significado de palabras desconocidas. Sin embargo, al terminar la clase de inglés, pude darme cuenta de que las diversas estrategias que fueron utilizadas en la clase y facilitadas por la profesora, efectivamente contribuyen a una mejor y mayor comprensión de textos en inglés.

Angélica, por su parte, describió su proceso de lectura de la siguiente manera:

Cuando leo en español la fluidez de los conocimientos es más rápida; leo tal vez sin fijarme mucho en las palabras o cómo están escritas, y pienso que se debe a mi condición de hablante nativa del español.
Pero cuando leo en inglés lo hago con mayor dedicación, prestando mayor atención a las palabras y a las estructuras de las oraciones para poder entender y captar la idea, y poder traducirla con coherencia al español. No sé si es una técnica o no, pero lo hago cuando leo en inglés; es prestar mayor atención a lo que estoy leyendo.

Cada uno de los estudiantes enfatizó los aspectos de la lengua a los que ellos prestaban mayor atención al momento de leer un texto. Se puede notar que el aspecto de la lectura en la LE, el cual ellos consideraron con mayor detenimiento, fue el vocabulario desconocido. Aunque en los ejemplos de los aspectos de la lengua solucionados por los estudiantes no se observaron mayores problemas en cuanto a estructuras gramaticales, en el aula de clases muchas de estas estructuras fueron explicadas por la docente y solucionadas entre todos los miembros de la clase. Esto se presentaba debido a que Julia siempre estaba en contacto con los estudiantes monitoreando su trabajo. Este monitoreo ayudó a los estudiantes a que identificaran las dudas sobre los aspectos gramaticales que ellos presentaron, y a que se resolvieran estas dudas durante la clase. Sin embargo, Mayela tenía bastante dominio sobre algunos aspectos gramaticales que la ayudaron a reconocer los verbos y tiempos verbales. Angélica siempre manifestaba en sus entrevistas que tenía dificultad con respecto al uso apropiado de cierto vocabulario técnico y desconocido, al igual que estructuras gramaticales como los adjetivos finalizados en -ed, pero que lograba obtener su significado por el contexto. Por su parte, 
Frank también señaló que tenía problemas con ciertas estructuras verbales, pero que los resolvía por el contexto y con la ayuda tanto del diccionario como del conocimiento previo que él poseía acerca del tema y de la lengua extranjera.

Uso de las estrategias cognoscitivas de lectura: ¿Proceso consciente o inconsciente?

Cada uno de los instrumentos de recolección de los datos utilizados para la realización de este estudio permitieron presentar la dicotomía existente entre el uso consciente o inconsciente de las estrategias cognoscitivas de lectura en la comprensión del texto escrito por parte de los estudiantes. Esta dicotomía se hizo ver en las entrevistas y conversaciones informales que el investigador sostuvo con la docente y los estudiantes.

Cuando el investigador entrevistó a Julia sobre si se pudiera hablar de un uso consciente de las estrategias cognoscitivas de lectura en la LE, ella respondió lo siguiente:

[...] yo creo que en cierta forma sí, de un $100 \%$, yo creo estar contenta con un 50\%. Aunque uno debe tener los pies sobre la tierra; este..., sí. Yo creo que los estudiantes sí lograron entender para qué sirve la predicción como una estrategia de lectura, por ejemplo: ¿Cuál es la influencia directa de la predicción en la activación del conocimiento previo? ¿Cómo detectar dónde están las fallas? ¿Por qué no comprendieron un texto escrito en inglés? ¿Por qué no lo supieron expresar? ¿Por qué no organizaron bien las ideas?
Yo creo que sí se logró en algunos casos; se puede decir que se dio un uso consciente de las estrategias cognoscitivas de lectura en la lengua extranjera.

Por su parte, los estudiantes consideraron que ellos habían utilizado de forma consciente las estrategias cognoscitivas de lectura en la LE, ya que era en esta lengua donde ellos habían tomado conciencia de su uso.

En una conversación con Mayela, ella explicó lo siguiente: "[...] creo que hice un uso consciente de las estrategias cognoscitivas de lectura en la lengua extranjera, porque fue en esta lengua donde las aprendí y ahora las utilizo en el español, y sobre todo utilizo con mayor frecuencia la predicción". Esta afirmación muestra que el uso de las estrategias cognoscitivas se hizo consciente en la LE, y que este reconocimiento y aprendizaje está siendo llevado a la L1.

Con el propósito de evidenciar cómo los estudiantes usaron sus estrategias de lectura en la LE, el investigador solicitó que los estudiantes realizaran protocolos de pensamiento en voz alta. Estas verbalizaciones en voz alta sobre lo que ellos hicieron durante la lectura del texto escrito en inglés, fueron grabadas en una cinta magnetofónica a fin de analizar su contenido. Este análisis del contenido de los protocolos fue la base para identificar las estrategias utilizadas por los estudiantes al momento de mostrar su comprensión del texto escrito en su L1 (Ericsson y Simon, 1993; Seng y Hashim, 2006). Los estudiantes verbalizaron sus pensamientos con base en lo que comprendieron del texto escrito en inglés durante la etapa de lectura. 
Se presenta el protocolo de pensamiento en voz alta de Mayela como un ejemplo de lo que ella hizo durante el proceso de la lectura, mientras estaba leyendo el cuarto segmento del TB sobre la Guerra Civil Española.

En el protocolo de Mayela, se nota cómo ella utilizó las estrategias de inferencia/predicción y de confirmación/ descarte a medida que abordaba el texto escrito en inglés durante la etapa de lectura. Lo que está resaltado en negrita es la información que el investigador usó para explicar y evidenciar el uso de las estrategias por parte de la estudiante. Lo que está en cursiva es lo que la estudiante dijo en inglés durante el protocolo:

Hoy voy a continuar haciendo mi mini versión en español del cuarto segmento del Texto Base sobre la Guerra Civil Española. Voy a revisar nuevamente... los aspectos más importantes sobre todo el segmento...ese es...el del fin de la guerra y el exilio, bueno, ya en clase dijimos de qué se trata. Voy a confirmar si verdaderamente esa lectura que hicimos de todo el párrafo tiene que ver con las predicciones del mismo [sic]. Entonces, voy a comenzar a leer, creo que debo comenzar primero, aquí... leer nuevamente cada párrafo para que no... es que si no es una traducción. Entonces, vamos a ver. Este título dice fin de la guerra y el exilio, es porque va a hablar sobre ¿qué pasó después de que terminó la guerra? Bueno, entonces, creo que lo que tengo que hacer es comenzar a leer primero [lee en voz alta la primera oración sobre Franco's dictatorship was the intitutionalisation of his victory, $\mathrm{y}$ se detiene]. Ok, Franco ya sé que fue un dictador, pero el hecho de que tenga un apóstrofe indica según lo que dijo la profe, que es algo de los posesivos... ajá, entonces, esto pertenece a esto y no es dictador sino dictadura... aquí es la dictadura de Franco. Was, verbo ser y está en pasado, fue y esta palabra que sigue, se me parece al español, esto debe ser institucionalización por la terminación de la palabra sation, ...entonces, de que hizo su institucionalización de su victoria. Sigo...eh, ajá, he, él...van a describir cómo fue su dictadura... interesante... aquí si hay palabras extrañas. Voy a seguir leyendo lo que dice aquí... eh... él had deliberated fought, ese had fought... como que está en pasado, pero pasado perfecto no simple, ajá, entonces, ¿qué hago con deliberated? ¿Lo traduzco ahí mismo o qué? A ver... entonces, diría 'había luchado', Franco por... había peleado deliberadamente, espero que no sea cognado falso.

Cuando Mayela expresa que va a revisar el párrafo con el fin de confirmar si verdaderamente el tema tenía relación con las predicciones que ella y el grupo de estudiantes hicieron en la clase, ella muestra el uso de la predicción/inferencia y de la confirmación/descarte como las estrategias que le permitieron resolver sus dudas con respecto al contenido del texto (Strauss, Goodman y Paulson, 2009). Estas estrategias indican cómo el lector realiza las conexiones entre su conocimiento previo y la información presente en el texto a medida que lee. 
Además, el uso de estas estrategias por parte de Mayela confirma lo que ella señaló en las entrevistas con respecto a que la predicción era una de las estrategias cognoscitivas que ella más utilizaba desde que comenzó a tomar los cursos de Inglés-Lectura.

En la frase n. ${ }^{\circ} 2$, tenemos otra evidencia de lo que Mayela hacía a medida que abordaba el texto: "creo que lo que tengo que hacer es comenzar a leer primero". En esta frase Mayela señala lo que debe hacer para abordar el texto y comprender su contenido, cuando ella dice: "creo que..."; en este caso, ella considera que debe abordar el texto haciendo la lectura correspondiente para confirmar o descartar sus predicciones, y construir las nuevas a medida que continúa leyendo (Hardin, 2001). Otro ejemplo del uso de las estrategias cognoscitivas de lectura y de las claves lingüísticas se presenta en el grupo de frases y oraciones n. ${ }^{\circ} 3$ : "Franco..., ya sé, quien fue un dictador, pero el hecho de que tenga un apóstrofe indica según lo que dijo la profe, que es algo de los posesivos... ajá, entonces, esto pertenece a esto y no es dictador sino dictadura".

El uso de las claves sintácticas y semánticas y las conexiones de estas con las estrategias de inferencia y corrección permiten deducir el significado de una palabra o frase. Cuando Mayela hizo referencia a la explicación de la profesora sobre los posesivos en inglés, ella estaba usando su conocimiento previo y los aspectos sintácticos de la LE para inferir la función gramatical de la palabra dictatorship, y darle el sentido correcto en español. Asimismo, se observa el uso de las claves sintácticas y semánticas tales como las terminaciones -ed en inglés para los verbos en participio pasado, y el reconocimiento de los cognados falsos y verdaderos. Esto se ejemplifica mejor en el grupo de frases y de oraciones n. ${ }^{\circ} 4$ :

\section{"Eh... él had deliberated fought,} ese had fought... como que está en pasado, pero pasado perfecto no simple, ajá entonces, ¿qué hago con deliberated? ¿Lo traduzco ahí mismo o qué? A ver... entonces, diría había luchado, Franco por... había peleado deliberadamente, espero que no sea cognado falso...”.

Aquí se presenta el conocimiento gramatical que Mayela tiene en cuanto a la LE, y cómo realizó las conexiones necesarias con la L1, creando ese puente para la comprensión. La frase $n .^{\circ} 5$, muestra el uso, como lectora, de sus estrategias cognoscitivas de lectura: "yo debo revisar esta versión antes de hacer la versión final en español".

Cuando Mayela expresa que va "a revisar la versión antes de hacer la versión final en español"; versión, en este caso, se refirió al segmento n. ${ }^{\circ} 4$, y la segunda versión de todos los segmentos que componen el texto escrito en inglés. Con esta frase, Mayela mostró su preocupación por lo que hizo como lectora, y decidió revisar lo que había hecho para su versión en español. Mayela demostró que el proceso de lectura no es mecánico y lineal, y que el lector, a medida que lee o aborda el texto escrito, puede revisar lo que va comprendiendo, comprobándose así que el uso de las estrategias cognoscitivas de lectura está sujeto a las necesidades del lector; en otras palabras, el estudiante puede ir hacia adelante o hacia atrás en el texto con el propósito de evaluar su comprensión (Crandall et al., 2002). 
Seng y Hashim (2006) señalan que los protocolos de pensamiento en voz alta son uno de los instrumentos de recolección de datos que evidencia el uso de las estrategias cognoscitivas de lectura y de las claves lingüísticas por parte de los estudiantes a la hora de abordar un texto escrito. Esta verbalización de los pensamientos permite identificar el uso de las estrategias cognoscitivas al analizar palabras, frases y oraciones que el lector produce oralmente a medida que lee el texto escrito.

\section{Discusión}

La primera pregunta de investigación que orientó este estudio se refiere al papel que juegan las estrategias cognoscitivas de lectura en el desarrollo de la comprensión lectora de textos escritos en inglés en un curso con fines académicos. La subpregunta trata acerca de qué manera las estrategias cognoscitivas de lectura sirven de base para el desarrollo de la comprensión de la lectura de textos escritos en una lengua extranjera. Durante el desarrollo del estudio, se observó cómo los estudiantes de un curso de inglés con fines académicos reconocieron, utilizaron y se apropiaron de sus estrategias cognitivas de lectura de forma consciente en la LE. Este uso y apropiación de las estrategias por parte de los estudiantes, cuando leían textos en la LE, fue el puente que los estudiantes emplearon para el desarrollo de la comprensión de la lectura.

Una evidencia de cómo los estudiantes hicieron uso de sus estrategias y del rol que estas jugaron en la comprensión de la lectura se encuentra en los protocolos de pensamiento en voz alta. A continuación, se presenta una sección del protocolo donde Mayela verbaliza sus pensamientos cuando lee el segmento número III del TB: Spanish Civil War exhibition:

Aquí sigue el autor hablando de lo qué paso en el bombardeo. A ver, sí la Guerra Civil estuvo simbolizada por el bombardeo a Guernica, seguro que el autor va a mostrar cómo se dio este bombardeo. Entonces, Guernica was part of... ¡ajá!, fue parte de...un trail run of the ground-air coordination, pero qué significa trail, porque groundair coordination tiene que ver con coordinación tierra-aire, tiene que ver con el tipo de ataque, pero... entonces, 'trail'. ¿A qué se referirá?...

En esta sección del protocolo, se observó cómo Mayela utilizó la predicción/inferencia y la confirmación y el descarte como las estrategias que le permitieron resolver sus dudas con respecto al contenido del texto. Asimismo, se muestra la construcción de nuevas predicciones y la confirmación y el descarte de estas, así como la identificación de las claves lingüísticas que le proveyó el texto (Durgunoglu y Öney, 1999; Grabe y Stoller, 2013; Portillo, 2000). Este uso consciente de las estrategias permite demostrar que juegan un papel preponderante en el proceso de la lectura, ya que le permite al lector reflexionar, adelantarse y retroceder durante el proceso lector con el propósito de revisar si está o no comprendiendo, lo que permitiría construir su propio significado. Un lector de una LE puede activar las estrategias cognoscitivas que ya posee en su L1 de forma inconsciente cuando lee un texto en una LE, apropiándose de estas de 
forma consciente; esto, por supuesto, facilita la comprensión del texto en una LE (Dechant, 2009; Goodman, 1981; Grabe y Stoller, 2013; Maming, 2019; Ramírez, 2003; Rumelhart, 1980).

Con base en la posición señalada por los estudiantes en las entrevistas semiestructuradas acerca del uso de las estrategias cognoscitivas de lectura, se podría afirmar que ellos, en esta investigación, hicieron uso de sus estrategias de forma consciente en la LE. Esto confirma los resultados del estudio realizado por Susser y Robb (1990) sobre la enseñanza explícita de las estrategias de lectura. Estos autores recalcan el uso consciente y la transferencia de las estrategias cognoscitivas de lectura de la L1 a la LE y viceversa. Con el propósito de dar respuesta a la subpregunta concerniente a la importancia de las estrategias cognoscitivas de lectura y de qué manera estas sirven de base en el desarrollo de comprensión de la lectura, es relevante mencionar cómo los estudiantes mostraron, mediante los protocolos de pensamiento en voz alta, el uso de sus estrategias. En estos protocolos los estudiantes reflexionaron sobre el contenido de lo que estaban leyendo. A medida que lo hacían, iban confirmando o descartando la información, construyendo así, sobre la base de sus predicciones, nuevas predicciones acerca del contenido del texto, seleccionando y reconociendo, en algunos casos, vocabulario relacionado con el contenido del escrito. De acuerdo con Dechant (2009), Goodman (1981), Grabe y Stoller (2013), Maming (2019), Ramírez (2003) y Rumelhart (1980), y con base en el Modelo Socio-PsicolingüísticoTransaccional de la lectura (Goodman, 1968; Strauss, Goodman y Paulson,
2009; Weaver, 2002), los lectores en LE, que hacen uso consciente de las estrategias como la predicción, pueden reconstruir el significado y comprender el contenido de un texto.

La segunda pregunta trató acerca de cómo se evidenció el uso de las estrategias de lectura en un curso de inglés con fines académicos. Las correspondientes subpreguntas trataron acerca del tipo de actividades de lectura en la L1, y si estas sirvieron de base para el desarrollo de estrategias de lectura cuando los estudiantes abordaron textos en la LE. También se consideró hasta qué punto los estudiantes reconocieron sus estrategias en la L1 para el desarrollo de la comprensión de textos en la LE.

Las actividades pedagógicas que se desarrollaron durante las diferentes sesiones de clase permitieron evidenciar cómo los estudiantes reconocieron y utilizaron sus estrategias de lectura. Durante las actividades llevadas a cabo por los estudiantes en la etapa de prelectura, se evidenció la activación del conocimiento previo por medio de la realización de los mapas semánticos. La información presente en estos mapas fue confirmada y/o descartada durante la etapa de lectura, y se observó cómo los estudiantes predijeron e infirieron sobre el posible contenido del texto (Dole et al., 1991; Grabe y Stoller, 2013; Graves y Cook, 1983; Stevens, 1982; Strauss, Goodman y Paulson, 2009).

Los protocolos de pensamiento en voz alta también sirvieron como una evidencia del uso de las estrategias cognitivas. Los mapas semánticos y las reflexiones escritas que produjeron los estudiantes fueron dos actividades que presentaban la información confirmada 
o descartada durante el proceso de la lectura. Cada una de las actividades diseñadas por la docente, facilitó la comprensión del texto. Durante las entrevistas, Frank señaló lo siguiente:

[...] las actividades desarrolladas en clase facilitaron la comprensión de la lectura de los textos en inglés. Asimismo, me permitieron conocer el uso de algunas estrategias que utilicé cuando leía en inglés, así como también reforzar las estrategias utilizadas en la lectura en español.

Mayela, por su parte, explicó que el trabajo realizado con la docente le sirvió de pauta para llevar a cabo las actividades con el TS. Mayela también señaló la importancia de las tutorías individuales, en las cuales Julia orientaba a los estudiantes para el desarrollo de las actividades tanto con el TB como con el TS. Las conclusiones a las que llegaron los estudiantes-informantes acerca de las actividades diseñadas por la docente permiten concluir que sirvieron de andamiaje para que los estudiantesinformantes reconocieran y utilizaran sus estrategias cognoscitivas de lectura (Pritchard, 2014; Vygotsky, 1978). Este andamiaje se refiere al apoyo que suministraron las actividades diseñadas por la docente con el propósito de que los estudiantes reconocieran, utilizaran y se apropiaran de las estrategias cognoscitivas de lectura.

El diseño e implementación de actividades pedagógicas explícitas es parte fundamental en el logro de la comprensión de la lectura, puesto que el lector tiene la oportunidad de iniciar/reconocer, muestrear/seleccionar, predecir/ inferir, confirmar/descartar y corregir/ finalizar (Dechant, 2009; Goodman, 1981, 1996; Maming, 2019; Ramírez, 2003; Rumelhart, 1980; Strauss, Goodman y Paulson, 2009). Estas ideas coinciden con lo que Salataci y Akyel (2002) señalan en su estudio acerca de los posibles efectos en la enseñanza explícita de las estrategias de lectura en L1 y en LE. Estos investigadores comprobaron que la enseñanza explícita y las actividades diseñadas por los docentes ayudan en el reconocimiento y uso consciente de las estrategias cognoscitivas de lectura en la LE. Asimismo, estos autores también comprobaron que las estrategias eran utilizadas con mayor frecuencia por los lectores en su L1.

Activar el conocimiento con preguntas y la elaboración de mapas semánticos, al igual que la identificación de las claves sintácticas y semánticas en el texto escrito en la LE, sirvió de puente para la comprensión. Por supuesto, el uso consciente de las estrategias de lectura en la LE estuvo fundamentado por el diseño e implementación de las actividades pedagógicas y la enseñanza explícita de estas estrategias. La activación del conocimiento previo es una fase en la etapa de prelectura que no se produce aisladamente del proceso de la lectura como tal. Esta se promueve con las actividades pedagógicas diseñadas e implementadas por el docente con el propósito de que los estudiantes revisen cuánto conocen sobre un tema. En este estudio las actividades implementadas por Julia para activar el conocimiento previo de los estudiantes acerca del texto relacionado con la Guerra Civil Española estuvieron centradas en preguntas que dieron como resultado la elaboración de mapas semánticos. Rowe y Rayford (1987) 
señalan el diseño y formulación de preguntas como una técnica pedagógica efectiva para la activación del conocimiento previo.

\section{Conclusiones}

Se puede concluir que activar el conocimiento previo permite que los estudiantes estén más conscientes y seguros de la información que van a encontrar en el texto escrito en la LE. Esta activación facilita que el lector realice las conexiones necesarias no solo en términos de estructuras gramaticales entre las dos lenguas, sino también en términos de contenido, posibilitando así la construcción del significado (Dole et al., 1991; Graves y Cook, 1983; Stevens, 1982). Este hallazgo corrobora los que algunos autores señalan acerca de la lectura en la LE, al considerar que la activación del conocimiento previo funge de puente para abordar el texto escrito (Grabe y Stoller, 2013). Asimismo, es importante señalar que la activación del conocimiento previo es una actividad que se puede utilizar en otros escenarios de enseñanza/aprendizaje. Un lector puede anticiparse al contenido de un tema, por predicciones en forma de preguntas y la realización de mapas semánticos que reflejen gráficamente cuánto conoce sobre un tema (Al-Ghazo, 2015; Heimlich y Pittelman, 1991; Rowe y Rayford, 1987).

Los resultados obtenidos acerca de la identificación de las claves lingüísticas del texto escrito corroboran lo que Salataci y Akyel (2002) señalan con respecto a que los lectores de una $\mathrm{LE}$ utilizan las claves lingüísticas del texto, y que este uso se evidencia cuando los lectores reconocen el significado de las palabras y las categorías gramaticales a las que pertenecen, así como la sintaxis de la oración con el propósito de darle sentido al texto. En este estudio, específicamente, los estudiantes identificaron en el texto las claves sintácticas y semánticas, las cuales sirvieron de coadyuvante en la comprensión del contenido del TB y del TS. Esto permite afirmar que cada lector posee sus propias estrategias de lectura, las cuales activa, dependiendo de sus necesidades como lector y a medida que aborda un escrito. Asimismo, el texto en sí posee claves lingüísticas que el lector emplea a medida que va avanzando en la lectura a fin de construir su propio significado. De acuerdo con el Modelo Socio-Psicolingüístico-Transaccional de la lectura, un texto por sí solo es incompleto; es el lector quien utiliza su conocimiento previo para obtener la información necesaria y construir significado (Rosenblatt, 1976).

En este estudio, se observó cómo los estudiantes emplearon las claves sintácticas y semánticas que proveyó el texto en la LE para comprender el contenido del escrito, al realizar conexiones a nivel sintáctico y semántico entre la LE y la L1. Estas conexiones permitieron que los estudiantes resolvieran sus dudas en cuanto a los aspectos de la LE que dificultaron la comprensión del texto. Es importante señalar la mediación por parte de la docente, ya que ella orientó a los estudiantes en la solución de los problemas o posibles dudas en cuanto a gramática o vocabulario. La participación constante de los estudiantes y las explicaciones que ellos dieron de cómo habían resuelto las dudas gramaticales, facilitó la comprensión de aquellos aspectos gramaticales 
de la lengua que Julia señaló. Asimismo, la ayuda de un compañero más capaz, representado bien sea por un compañero de la clase o por la docente, también facilitó la solución de los problemas relacionados con la gramática y el vocabulario (Vygotsky, 1978).

Las claves semánticas presentes en el texto fueron utilizadas con mayor frecuencia por los estudiantes. Para la solución de problemas con el uso de los cognados, por ejemplo, los estudiantes hicieron las conexiones entre la LE y la L1 a nivel semántico, tomando en cuenta que la grafía no era una condición para considerar que todas las palabras en la LE eran cognados verdaderos (Alderson, Brunfaut y Hardin, 2017; Cohen, 2014; Grabe y Stoller, 2013). Con el propósito de que los estudiantes se apropiaran del significado de muchas palabras y de conocer cuánto habían entendido sobre el tema, Julia solicitó que los estudiantes realizaran una versión por escrito sobre el contenido del texto, a fin de revisar no solo los cognados sino también los aspectos gramaticales y de vocabulario.

Los resultados de este estudio permiten concluir que los estudiantes hicieron uso de las estrategias cognoscitivas de lectura de forma consciente. Ellos, orientados por la docente, reconocieron y usaron conscientemente sus estrategias cognoscitivas de lectura y las claves lingüísticas del texto para comprender el texto escrito en inglés. Esta aseveración parece corroborar la posición presentada por algunos autores quienes afirman que es en la LE en donde algunos lectores reconocen, utilizan y se apropian de las estrategias cognoscitivas de lectura y de las claves lingüísticas presentes en el texto (Cummins, 1989; Grabe y Stoller, 2013;
Jiménez, García y Pearson, 1995; Koda, 1988). Aunque los estudiantes poseen sus estrategias en su L1, en muchos casos no hacen uso de éstas de forma consciente, sino que las activan y utilizan de forma consciente cuando leen un texto escrito en una LE, dependiendo de sus necesidades como lectores (Hardin, 2001; Kristin, 2017; Levine y Reves, 1985).

$\mathrm{Al}$ igual que en otras investigaciones de corte cualitativo enmarcadas en contextos de enseñanza/aprendizaje de una LE, este estudio pretende proponer líneas de investigación que permitan profundizar en el tema del uso de las estrategias cognoscitivas de lectura para el desarrollo de la comprensión de textos escritos en inglés en cursos con fines académicos. Con el propósito de establecer estas líneas de investigación, se formulan las siguientes interrogantes:

- ¿Hasta qué punto el uso consciente de las estrategias cognoscitivas de lectura en la LE funciona como un atenuante para que se pueda dar una transferencia de estas estrategias de la LE a la L1?

- ¿De qué manera los docentes de una LE con fines académicos pueden promover la transferencia de las estrategias cognoscitivas de lectura a la L1?

Estas y otras preguntas vinculadas con el uso de las estrategias cognoscitivas de lectura podrían servir de base para el desarrollo de nuevas investigaciones enmarcadas en un contexto de enseñanza/aprendizaje de una LE en diferentes latitudes. 


\section{Bibliografía}

Alderson, C., Brunfaut, T. y Harding, L. (2017). Bridging assessment and learning: a view from second and foreign language assessment. Assessment in Education: Principles, Policy \& Practice, 24, 379-387.

Al-Ghazo, A. (2015). The effect of SQ3R and semantic mapping strategies on reading comprehension learning among Jordanian university students. International Jourdan of English and Education, 4 (3), 92-106.

Barnett, M. (1989). More than meets the eye. Foreign language. Theory and practice. Prentice Hall Regents.

Cho, K.S., Kyoung-Ok, A., y Krashen, S. (2005). The effects of reading authentic texts on interest and reading ability in English as a foreign language. Reading Improvement, 42 (1), 58-65.

Cohen, A. D. (2014). Strategies in learning and using a second language. Routledge.

Crandall, J., Jaramillo, A., Olsen, L., y Peyton, J. K. (2002). Using cognitive strategies to develop English language and literacy. Center for Applied Linguistics.

Creswell, J. W. y Creswell, J. D. (2018).Researchdesign:Qualitative, quantitative, and mixed methods approaches (5 $5^{\text {th }}$ ed.). SAGE Publications.

Cummins, J. (1989). Language and literacy acquisition in bilingual contexts. Journal of Multilingual and Multicultural Development, 10, 17-31.

Dechant, E. (2009). Understanding and teaching reading: An interactive model. Lawrence Erlbaum.
Denzin, N. K. y Lincoln, Y. S. (2018). The SAGE handbook of qualitative research $\left(5^{\text {th }}\right.$ ed.). SAGE Publications.

Dole, J. A., Valencia, S. W., Greer. E. A., y Wardrop, J. L. (1991). Effects of two types of prereading instruction on the comprehension of narrative and expository text. Reading Research Quarterly, 26 (2), 142-159.

Durgunoglu, A. Y., y Öney, B. (1999). A cross linguistic comparison of phonological awareness and word recognition. Reading and Writing, 11, 281-299.

Ericsson, K., y Simon, H. (1993). Protocol analysis. Verbal reports as data. A Bradford Book.

Goodman, K. (Ed.). (1968). The psycholinguistic nature of the reading process. Wayne State University Press.

Goodman, K. (1981). Miscue analysis and future research directions. En S. Hudelson (Ed.), Learning to read different languages. Linguistics and literacy series (pp. ix-xiii). Center for Applied Linguistics.

Goodman, K. (1982). El proceso de la lectura: Consideraciones a través de las lenguas y del desarrollo. En E. Ferrero y M. García Palacio. Nuevas perspectivas sobre los procesos de lectura y escritura (pp. 13-28). Siglo XXI.

Goodman, K. (1996). Ken Goodman on reading. A common-sense look at the nature of language and the science of reading. Heinemann.

Goodman, K. (2014). What's whole in Whole Language in the 21 st century. Gran Press, LLC.

Grabe, W., y Stoller, F. L. (2013). Teaching and researching reading (2nd ed.). Routledge. 
Graves, M. F., y Cook, C. L. (1983). Effects of previewing difficult short stories on low ability junior high school student's comprehension, recall, and attitudes. Reading Research Quarterly, 18 (3), 262-267 [EJ 279344].

Hardin, V. B. (2001). Transfer and variation in cognitive reading strategy of Latino fourth-grade students in a late-exit bilingual program. Bilingual Research Journal, 25 (4), 539-561.

Heimlich, J., y Pittelman, S. (1991). Estudiar en el aula. El mapa semántico. Aique Grupo Editor.

Hutchinson, T., y Waters, A. (1987). English for specific purposes. Cambridge University Press.

Hyland, K. (2006). English for academic purposes: an advanced resource book. Routledge.

Hyland, K. (2018). Metadiscourse: Exploring interaction in writing. Routledge.

Jiménez, R., García, G., y Pearson, P. (1995). Three children, two languages, and strategic reading: case studies in bilingual/monolingual reading. American Educational Research Journal, 32, 67-97.

Kerper, J. (2002). Metalinguistic transfer in Spanish/English biliteracy. En http://ce.sdsu.edu/people/jmora/MoraModules/MetalingTransfer.htm

Klingner, J. K., Vaughn, S., y Boardman, A. (2015). Teaching reading comprehension to students with learning difficulties. The Guilford Press.

Koda, K. (1988). Cognitive process in second language reading: Transfer of L1 reading skills and strategies. Second Language Research, 4, 133-156.
Kristin, M. (2017). Meeting the needs of avid book readers: Access, space, concentration support and barrier mitigation. Journal of Library Administration, 57, 1, 49-68.

Lantolf, J. P., y Poehner, M. E. (2014). Sociocultural theory and the pedagogical imperative in L2 education. Vygotskian praxis and the theory/practice divide. Routledge.

Levine, A., y Reves, T. (1985). What can the FL teachers teach the mother tongue readers? Reading in a Foreign Language, 3, 329-339.

Maming, K. (2019). Activating EFL learners by integrating team-based learning with collaborative strategic reading. LITERA, 18 (2), 297-311.

Merriam, S. (2016). Qualitative research: $A$ guide to design and implementation. John Wiley \& Sons, Inc.

Portillo, R. (2000). Estrategias para el desarrollo de la competencia gramatical: español e inglés. Hacia una enseñanza intercultural de las lenguas. En www.mec.es/redele/biblioteca/asele/00.presentación.pdf

Pritchard, A. (2014). Ways of learning. Learning theories and learning styles in the classroom ( $\left.3^{\text {rd }} \mathrm{ed}\right)$. Routledge.

Ramírez, D. (2003). Cognitive reading instruction for FL learners of technical English. En http://www. readingmatrix.com/conference/pp/ prodecing/verdugo.pdf

Rosenblatt, L. (1976). Literature as exploration. The Modern Language Association of America.

Rowe, D. W., y Rayford, L. (1987). Activating background knowledge in reading comprehension assessment. Reading Research Quarterly, 22 (2), 160-176. 
Rumelhart, D. (1980). Schemata: the building blocks of cognition. En J. Rand, C. Betram, y W. E. Brewer (Eds.), Theoretical issues in reading comprehension (pp. 32-58). Lawrence Erlbaum Ass, Publishers.

Salataci, R., y Akyel, A. (2002). Possible effects of strategy instruction on L1 and L2 reading. Reading in a Foreign Language, 14, 1-17.

Seng, G. H., y Hashim, F. (2006). Use of L1 in L2 reading comprehension among tertiary ESL learners. Reading in a Foreign Language, 18, 29-54.

Stevens, K. C. (1982). Can we improve reading by teaching background information? Journal of Reading, 25(4), 326-329.

Strauss, S. L., Goodman, K., y Paulson, E. (2009). Brain research and reading: How emerging concepts in neuroscience support a meaning construction view of the reading process. Educational Research and Review, 4 (2), 021-033.

Susser, B., y Robb, K. S. (1990). EFL extensive reading instruction: Research and procedure. JALT Journal, 12, 161-186.

Vygostky, L. (1978). Mind in society. Harvard University Press.

Weaver, C. (2002). Reading process and practice. From sociopsycholinguistics to Whole Language (3rd ed.). Heinemann.

Wingate, U., y Tribble, Ch. (2012). The best of both worlds? Towards an English for academic purposes/academic literacies writing pedagogy. Studies in Higher Education, 37 (4), 481-495.

Yin, R. K. (2018). Case study research and applications: Design and methods. SAGE Publications. 


\section{Anexo 1}

Hoja de observación utilizada en la investigación

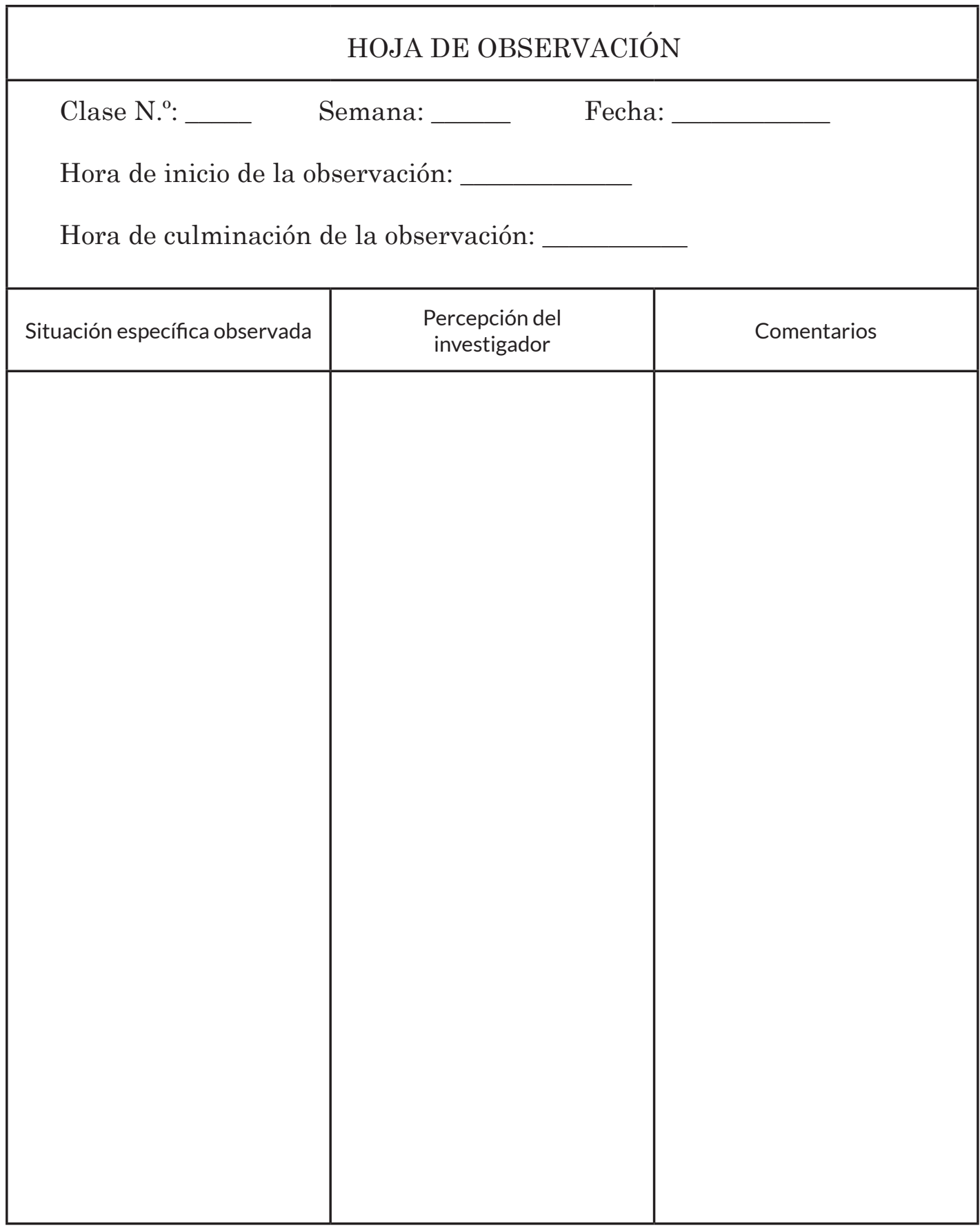




\section{Anexo 2}

\section{Temas tratados en las entrevistas semiestructuradas con los estudiantes}

\section{Anexo 2 (a). Primera entrevista:}

Definición de la lectura.

Cantidad de lectura en español. Si la respuesta es afirmativa, tipo de textos que lee el estudiante; si es negativa, razones.

Cantidad de lectura en inglés. Si la respuesta es afirmativa, tipo de textos que lee el estudiante; si es negativa, razones.

Gusto por el inglés.

Contacto con el inglés. Forma de contacto con el inglés.

Nivel de conocimiento del inglés para comprender textos escritos en ese idioma. Actividades para practicar el inglés.

\section{Anexo 2 (b). Segunda entrevista:}

Papel que juegan las estrategias cognoscitivas de lectura para el desarrollo de la comprensión de la lectura en inglés, según las actividades que la docente ha realizado en clase.

Importancia de las estrategias y si estas ayudan en la comprensión de textos escritos en inglés.

Actividades para comprender un texto escrito en español y en inglés, semejanzas y diferencias.

Definición de estrategias de lectura.

\section{Anexo 2 (c). Tercera entrevista:}

Importancia de las estrategias cognoscitivas de lectura implementadas por la docente, y si fueron la base fundamental para la comprensión de los diferentes textos escritos en inglés que leyeron durante el semestre.

Importancia del uso de las diferentes estrategias cognoscitivas de lectura que implementó la docente durante el semestre y cómo se evidenció este uso en el curso de inglés con fines académicos.

Cuánto y de qué manera ayudó el uso de las estrategias de lectura en el desarrollo de la comprensión de textos escritos en inglés. 


\section{Anexo 3}

\section{Temas tratados en las entrevistas semiestructuradas con la docente}

\section{Anexo 3 (a). Primera entrevista:}

Concepción/definición de la lectura.

Definición de estrategias cognoscitivas de lectura.

Tipo de actividades que se pueden diseñar para el desarrollo de las estrategias cognoscitivas de lectura en un curso de inglés como LE con fines académicos. Forma de implementar estas estrategias en un curso de inglés como LE con fines académicos.

\section{Anexo 3 (b). Segunda entrevista:}

Concepción/definición de la lectura, ¿cambios?

Progreso de los estudiantes luego de la implementación de actividades para el desarrollo de la comprensión de la lectura.

Implementación de las estrategias cognoscitivas de lectura como la base fundamental para que los estudiantes pudieran comprender los diferentes textos escritos en inglés que leyeron durante el semestre.

Actividades de lectura en la L1 diseñadas como base para el desarrollo de estrategias cognoscitivas de lectura, especialmente cuando los estudiantes abordaron los textos escritos en inglés como LE.

Papel que juega el reconocimiento de las estrategias cognoscitivas de lectura por parte de los estudiantes en el momento cuando abordan un texto escrito en inglés como LE. 